\title{
De Lamartine, Correspondance, Lettres à Valentine Cessiat (1841-1854)
}

\section{Lise Sabourin}

\section{(2) OpenEdition}

10 Journals

\section{Édition électronique}

URL : http://journals.openedition.org/studifrancesi/10661

DOI : 10.4000/studifrancesi.10661

ISSN : 2421-5856

Éditeur

Rosenberg \& Sellier

\section{Édition imprimée}

Date de publication : 1 décembre 2017

Pagination : 561-562

ISSN : 0039-2944

\section{Référence électronique}

Lise Sabourin, «De Lamartine, Correspondance, Lettres à Valentine Cessiat (1841-1854) », Studi Francesi [En ligne], 183 (LXI | III) | 2017, mis en ligne le 01 février 2018, consulté le 22 janvier 2021. URL : http:// journals.openedition.org/studifrancesi/10661; DOI : https://doi.org/10.4000/studifrancesi.10661

Ce document a été généré automatiquement le 22 janvier 2021.

\section{(c) (i) (9)}

Studi Francesi è distribuita con Licenza Creative Commons Attribuzione - Non commerciale - Non opere derivate 4.0 Internazionale. 


\title{
De Lamartine, Correspondance, Lettres à Valentine Cessiat (1841-1854)
}

\author{
Lise Sabourin
}

\section{RÉFÉRENCE}

ALPHONSE DE LAMARTINE, Correspondance, Lettres à Valentine Cessiat (1841-1854), édition de Christian Croisille, Paris, Honoré Champion, 2014, 355 pp.

1 Parmi les nombreux correspondants de Lamartine émergent des amis essentiels, tel Aymon de Virieu dont Marie-Renée Morin nous avait fourni les lettres, mais aussi cette nièce si chère à son cœur qu'est Valentine de Cessiat. Christian Croisille présente dans ce supplément à la Correspondance générale les missives que lui écrivit le poète de 1841 à 1854 , avec quatre de ses réponses, seules conservées. Munie d'une bonne introduction (pp. 7-34), d'une chronologie des années concernées, d'une note bibliographique et des index des œuvres de Lamartine, des noms et des titres de journaux, cette édition a l'avantage d'enrichir la première parution assurée en 1928 par le comte de Chastellier, descendant de Léontine de Belleroche, nièce légataire de Valentine. Christian Croisille rétablit des passages coupés par souci de bienséance familiale et amplifie la connaissance de ces lettres puisque leur nombre passe de 131 à 213, pour la plupart maintenant déposées à la bibliothèque de l'Université de Syracuse aux USA.

Parmi sa nombreuse famille, Lamartine a vraiment entretenu avec cette troisième fille de sa sœur Cécile une relation à part. Tout commença par la mission donnée par la mère de la jeune fille de tenir son frère informé de son voyage à Nice en décembre 1841 . Lamartine fut si content de l'épistolière qu'il continua et amplifia l'échange, confiant peu à peu à cette jeune femme de trente ans de moins que lui la charge de surveiller les vignes, puis les comptes des terres mâconnaises familiales pendant ses séjours parisiens hivernaux. Progressivement son «homme d'affaires», comme il la dénommait plaisamment, devint son attachée de presse locale au fil de son ascension politique. C'est ainsi à elle qu'il prend le temps d'envoyer le texte de son discours de janvier 1843, 
de faire connaître le succès de son Histoire des Girondins, puis de relater les événements de février 1848: Valentine bien sûr lisait à sa mère et à ses sœurs, mais aussi à la société mâconnaise où elle vivait dans l'hôtel familial indivis ces nouvelles de Paris qui alimentaient la presse régionale. Elle adressait en retour des informations au grand homme sur la perception de sa popularité en province.

3 À partir de 1849, quand commença le déclin de sa carrière politique, puis que s'accentuèrent les soucis financiers, elle devint la confidente intime des souffrances de Lamartine, livré à la nécessité de devoir produire pour étancher les dettes accumulées. Trop optimiste dans l'usage de ses avances éditoriales, susceptible de se lancer dans des voyages coûteux (dès 1844 à Naples et Ischia avec sa femme Marianne, sa sœur Cécile et quatre de ses enfants, dont Valentine) ou des aventures inconsidérées (comme le placement à Smyrne en 1849-50), Lamartine, on le sait, finira en véritable servage littéraire par le Cours familier de littérature.

4 Entretemps, sa correspondance avec Valentine a cessé, non par brouille ou par décès comme pour Virieu, mais par réunion des deux épistoliers dans l'appartement parisien. En effet, après un séjour au printemps 1854 avec sa mère, Valentine finit par s'installer seule tous les hivers chez les Lamartine tout en les raccompagnant l'été dans leurs terres. Ainsi cette jeune femme restée célibataire malgré trois demandes en mariage (avortées au moins pour l'une par l'opposition de son oncle) finit-elle par tenir, après la mort de Marianne en 1863, le foyer du poète et se faire, aux côtés de Ronchaud, la vestale de son œuvre après sa disparition en 1869.

5 C'est dire combien cette amitié tendre a suscité d'hypothèses, depuis celle d'une substitution filiale après la mort de Julia jusqu'à un mariage secret dont la preuve n'a jamais été donnée. Sans doute faut-il plutôt chercher du côté de Graziella, par superposition à la défunte Antoniella, ou de Laurence auprès d'un Jocelyn qui ose fissurer pour elle la carapace de son image publique et s'épancher dans sa bienveillante proximité morale. 